\title{
Responsabilidad internacional por SARS-CoV-2 según el marco normativo de la Organización Mundial de la Salud
}

\author{
Dr. Fernando Villamizar Lamus \\ Universidad Bernardo O'Higgins \\ fvillamizar@ubo.cl \\ Código ORCID: https://orcid.org/0000-0003-0967-1161
}

\section{Mg. Constanza Sepúlveda Riquelme}

Universidad Bernardo O'Higgins

consepulveda@docente.ubo.cl

Código ORCID: https://orcid.org/0000-0002-3245-0116

\section{Resumen:}

El virus SARS-CoV-2 ha causado grandes estragos en el mundo, no solo en materia sanitaria, sino también en materia política, económica, psicológica y social. Dados los efectos nefastos de este virus, muchas voces claman y clamarán por algún tipo de reparación o que se determine a los responsables de la expansión del mismo. En este contexto, la figura del Derecho Internacional Público de la responsabilidad por el hecho internacionalmente ilícito toma relevancia como mecanismo jurídico. El presente artículo hará un recorrido teórico de la Responsabilidad por el hecho ilícito internacional, aplicado al caso de una eventual reclamación internacional por los efectos del SARS-CoV-2. Para determinar las presuntas normas internacionales incumplidas se acudirá a las regulaciones normativas de la Organización Mundial de la Salud, se analizará si procede o no la responsabilidad a la luz de los hechos y normas y se examinará la forma en que la Constitución de la Organización Mundial de la Salud (OMS) y el Reglamento Sanitario Internacional (RSI) establecen los métodos de solución pacífica de controversia y lo que podría pasar en cada uno de dichos métodos. El principal hallazgo será que la complejidad del caso y la concatenación de métodos de solución de controversias de la Constitución de la OMS y del RSI hacen que las eventuales soluciones de las mismas sean muy dilatadas en el tiempo. En la metodología empleada para el análisis de la situación, se acudirá a los criterios que en materias afines se han consagrados en distintos fallos de la Corte Internacional de Justicia.

Palabras clave: COVID-19; hecho internacionalmente ilícito; Organización Mundial de la Salud; responsabilidad internacional; solución de controversias OMS

\footnotetext{
* Doctor en Ciencia Política y Sociología, Universidad Pontificia de Salamanca. Magíster en Derecho de la Empresa, Pontificia Universidad Católica de Chile. Abogado de la Universidad del Rosario, Bogotá, Colombia. Profesor de Derecho Internacional Público, Universidad Bernardo O’Higgins, Chile. Actualmente se desempeña como Director de la Escuela de Derecho de la Universidad Bernardo O’Higgins. Correo electrónico: fvillamizar@ubo.cl.

${ }^{* *}$ Magíster en Derecho, Universidad de Talca. Abogada Universidad Bernardo O'Higgins, Santiago, Chile. Ayudante de la cátedra de Derecho Internacional Público, Universidad Bernardo O'Higgins. Correo electrónico: consepulveda@docente.ubo.cl
} 


\begin{abstract}
:
"International responsibility for SARS-CoV-2 according to the normative framework of the World Health Organization". SARS-CoV-2 has caused great havoc in the world, not only in health affairs, but also in political, economic, psychological and social matters. Given the dire effects of this virus, many voices cry out and will continue crying out for some kind of repair or for determining those responsible for the virus' expansion. In this context, the figure of Public International Law of responsibility for the internationally wrongful act takes relevance as a legal mechanism. The article here presented offers a theoretical overview of Responsibility for the international wrongful act, applied to the case of an eventual international claim for the effects of SARS-CoV2. In order to determine the presumed international norms that have not been complied with, the normative regulations of the World Health Organization will be pointed out. Whether or not liability is appropriate in light of the facts and rules will be analyzed and the way in which the Constitution of the World Health Organization (WHO) and the International Health Regulations (IHR) establishes the methods for the peaceful settlement of controversies and what could happen in each of these methods will be examined. The main finding will be that the complexity of the case and the concatenation of dispute resolution methods of the WHO Constitution and the RSI make the eventual solution of the same very long in time. Regarding the methodology used for the analysis of the situation, the criteria used in related matters enshrined in different rulings of the International Court of Justice will be employed.
\end{abstract}

Keywords: COVID-19; dispute resolution WHO; international liability; international wrongful act; Word Health Organization

Recibido: 15.10 .2020

Aceptado: 05.12.2020 


\section{Introducción}

Pensar que una situación puntual acaecida en un lugar lejano y poco conocido del planeta podría generar una pandemia que cambie la forma de vivir y que tenga en ascuas a la humanidad era hasta hace poco tiempo atrás algo propio de una película de ficción como "Contagio" (2011), en la cual Matt Damon y su familia debían vivir los rigores de un virus que afectaba a todo el globo terráqueo. Hoy el SARS-CoV-2, mejor conocido como y en adelante COVID-19, ha hecho que la realidad haya superado, o por lo menos igualado, a la ficción. Como es de esperar, ante los duelos por la pérdida de los seres queridos que sucumbieron ante las consecuencias del virus y las frustraciones y alto impacto económico que ha generado toda la pandemia, no faltan las voces de profesionales del Derecho que afirman, y dan por sentado, el arribo de demandas judiciales para reparar los daños causados por COVID 19 (Introvigne, 2020).

En ese contexto, el presente artículo tiene como objetivo analizar, en un marco normativo restringido, la Constitución de la Organización Mundial de la Salud y las posibles obligaciones internacionales incumplidas con ocasión de la pandemia. La hipótesis de estudio consiste en que dados los elementos de la responsabilidad por el hecho internacionalmente ilícito, atribución de la conducta del Estado o elemento subjetivo e incumplimiento de la obligación internacional del Estado o elemento objetivo (Crawford y Olleson, 2010, p. 453), la responsabilidad en el marco normativo de la Organización Mundial de la Salud ${ }^{1}$ podría erigirse, pero los métodos de solución de controversias contenidos en dicho instrumento jurídico internacional, van a hacer difícil que dicha responsabilidad se materialice en un fallo judicial.

Para efectos de desarrollar el tema y comprobar la hipótesis planteada, en primer lugar, se revisará lo concerniente a la responsabilidad internacional de los Estados en términos generales. Una vez visto y analizado el tema anteriormente enunciado, se analizarán los hechos acaecidos por los cuales se podría imputar responsabilidad del Estado, en el marco de la Constitución de la Organización Mundial de la Salud y el Reglamento Sanitario Internacional, bajo el prisma del cumplimiento o incumplimiento de las normas internacionales allí contenidas y de la atribución al Estado incumplido. En una tercera etapa, se estudiarán los métodos de solución de controversias y cómo estos podrían propender o no a una pronta resolución de los conflictos generados por la COVID-19. Finalmente se plantearán las conclusiones a las que haya lugar.

\section{Sobre la responsabilidad de los Estados}

Tal y como lo plantea el célebre jurista Paul Reuter "la responsabilidad es el corazón del Derecho Internacional" (Reuter, 1991, p. 390), entendiendo dicha institución jurídica como aquella según la cual a un sujeto de Derecho Internacional le es imputable un acto o comportamiento contrario a sus obligaciones internacionales, y, por ende, debe reparar al sujeto de Derecho Internacional que es víctima (Ruzié y Teboul, 2015). En ese sentido, la responsabilidad internacional es un principio fundamental del Derecho Internacional (Shaw, 2011), o lo que es más contundente aún: un corolario². A diferencia de lo que ocurrió en algunos Estados de Europa occidental durante su consolidación, en que se aplicaba la máxima "el rey no se equivoca" ("the King can do no wrong"), en el Derecho Internacional Público esto no es posible, porque, mientras en el plano interno la soberanía juego un rol sin límites en principio, en el plano internacional la soberanía se equipara entre Estados que tienen el mismo status (Pellet, 2010). Así, tal y como lo planteó la Corte Permanente de Justicia Internacional el caso Wimbledon "la posibilidad por la cual un Estado incurre en responsabilidad, corresponde a un atributo de la soberanía estatal" (Reino Unido, Francia, Italia y Japón c. Alemania, 1923). La responsabilidad internacional del Estado es una institución que se ha configurado 
esencialmente de manera consuetudinaria. Esto debido a que si bien es "la hora de la verdad del Derecho Internacional y el orden en la cual prospera" (Benchikh, 2018, p. 621), no es fácil que cualquier Estado del mundo acepte la determinación de reglas que puedan servir para establecer su responsabilidad internacional (Benchikh, 2018), como se verá más adelante cuando se trate el proyecto de la Comisión de Derecho Internacional sobre el tema.

Una de las primeras alusiones directas a la responsabilidad del Estado antes de la configuración estatal de Westfalia fue la realizada por Hugo Grocio, quien en 1625 expresó que cualquier daño causado conlleva la obligación por el Derecho Natural de hacer una reparación por el daño, si es que hay alguno. Desde luego, este concepto fundamental se implanta y evoluciona en el ámbito del Derecho Internacional, de manera que en la jurisprudencia de la primera parte del siglo $\mathrm{XX}$ se encuentra claramente expresado, como por ejemplo en los siguientes casos juzgados por la Corte Permanente de Justicia Internacional (CPJI): (i) Caso del vapor Wimbledon, en el cual la CPJI estableció que, por el hecho de haber negado el paso por el canal de Kiel al vapor Wimbledon, Alemania es responsable por el daño causado y debe compensar al gobierno francés (Reino Unido, Francia, Italia y Japón c. Alemania, 1923); (ii) Caso de la fábrica de Chorzów, en el cual la CPJI consideró como principio de Derecho Internacional la obligación de reparar como resultado de toda violación de un compromiso internacional (Alemania c. Polonia, 1928).

En la segunda mitad del siglo XX y con el inicio de las funciones de la Corte Internacional de Justicia (CIJ), los principios sobre responsabilidad del Estado se mantuvieron. De hecho, en el primer caso de conocimiento de la ClJ, el famoso caso del Estrecho de Corfú, ésta consideró responsable a Albania por las explosiones de unas minas que le causaron daños a dos buques de guerra británicos cuando navegaban en el mencionado Estrecho. En el análisis de la ClJ, el fundamento de la responsabilidad se sustentaba en la obligación de Albania de conocer que su territorio era usado para actitudes contrarias a los derechos de otros Estados (Reino Unido de Gran Bretaña y el Norte de Irlanda, 1949), con lo cual el concepto del control sobre las actividades que se hacen al interior del $\mathrm{Estado}^{3}$, hace parte fundamental para los efectos de generar responsabilidad internacional. Este concepto del control se enriquece con el caso Nicaragua, en el cual Estados Unidos proveyó apoyo de diverso tipo a los paramilitares nicaragüenses contrarios al régimen sandinista, los llamados "contras", y en el cual la CIJ decidió que aquella conducta era una violación del Derecho Internacional imputable a Estados Unidos (Caso concerniente a las actividades militares y paramilitares en y contra Nicaragua, 1986).

De manera más reciente, hay dos casos, de la multitud que puede invocarse como ejemplo, que también son íconos en lo relativo a la responsabilidad internacional del Estado. Por una parte, es relevante tratar el caso "Rainbow Warrior", en el cual dos agentes que actuaban por Francia hundieron la embarcación del mencionado nombre en aguas territoriales de Nueva Zelanda. Tras una mediación del Secretario General de Naciones Unidas, las partes celebraron un tratado en 1986, en virtud del cual a Francia se le obligó a pagar una indemnización a Nueva Zelanda y a trasferir a los dos agentes a una base francesa en el Pacífico, en la que estarían por tres años y de la que no saldrían sin el mutuo consentimiento de ambos Estados. Posteriormente, los agentes franceses fueron repatriados a Francia metropolitana sin el consentimiento de Nueva Zelanda, lo que causó la invocación por parte de Nueva Zelanda de una cláusula arbitral del tratado de 1986, con la cual el caso se decidió en arbitraje. Nueva Zelanda argumentaba el incumplimiento de las obligaciones del tratado de 1986 y Francia se defendió bajo el argumento de una fuerza mayor en la repatriación de los agentes que no podía controlar (ONU, 2006). 
El caso se decidió a favor de Nueva Zelanda porque los árbitros no encontraron justificada la fuerza mayor alegada por Francia. Lo relevante de este caso, para los efectos de este artículo, es que el incumplimiento del acuerdo internacional, así no haya generado daño aparente a una de las partes, generó responsabilidad internacional de Francia por el incumplimiento de una obligación internacional que le era imputable. Por otra parte, el caso Gabčíkovo-Nagymaros también es relevante, tanto como referente en general de la responsabilidad internacional del Estado, como antecedente relevante para el análisis que se hará más adelante. En este caso, Hungría abandonó la construcción de una represa a la cual estaba obligada por un acuerdo internacional. La $\mathrm{CIJ}$ decidió que Hungría no satisfizo los requerimientos para sustentar un estado de necesidad en virtud de un presunto daño ambiental que se causaría con la continuación de los trabajos (Caso concerniente al Proyecto Gabčíkovo-Nagymaros, 1997).

Ahora bien, ¿por qué son tan relevantes estos fallos para abordar el tema de la responsabilidad del Estado por el hecho ilícito internacional? Porque, como se mencionó anteriormente, la institución sub examine es considerada por algunos autores como reglas de Derecho Consuetudinario (Benchikh, 2018), debido a que no hay un tratado en vigor sobre esta materia. Esta posición debe ser aclarada, pues, si bien no existe un tratado general en materia de responsabilidad del Estado por el hecho ilícito internacional en vigor - y en ese sentido rigen las reglas consuetudinarias reflejadas en diversos fallos, como los expuestos anteriormente-, hay algunas convenciones particulares en materia de responsabilidad, como, por ejemplo, la Cuarta Convención de La Haya de 1907, que giró en torno a la responsabilidad en razón de los actos cometidos por las fuerzas armadas en campaña (Reglamento relativo a las leyes y costumbres de la guerra terrestre, 1907); el Convenio sobre la responsabilidad internacional por daños causados por objetos espaciales (Organización de las Naciones Unidas [ONU], 2002); el Convenio Internacional sobre Responsabilidad Civil por daños causados por la contaminación de las aguas del mar por hidrocarburos realizado en Bruselas el 29 de noviembre de 1969; entre otras.

Sin embargo, que no exista un tratado en vigor sobre la materia, no significa que no se ha intentado celebrarlo. El proceso codificador tiene sus orígenes en la Conferencia de Ginebra de 1930, con la cual se pretendía generar un tratado en la materia, concretamente sobre responsabilidad de los Estados por daños causados a extranjeros (Casanovas y Rodrigo, 2018), pero por desavenencias entre los participantes no fue posible adoptar un texto siquiera (Daillier et al., 2009). En 1955 se retoma este objetivo por parte de la Comisión de Derecho Internacional, creada en 1947. Tras el trabajo de cinco relatores especiales, F. V. García-Amador, R. Ago, W. Riphagen, G. Arangio-Ruiz y J. Crawford, en 2001 la Comisión de Derecho Internacional aprobó un Proyecto de artículos sobre responsabilidad de los Estados por hechos internacionalmente ilícitos, respecto del cual la Asamblea General de Naciones Unidas se manifestó, en la Resolución 56/83 de 2001, en el siguiente sentido:

1. Acoge con beneplácito la conclusión de la labor de la Comisión de Derecho Internacional respecto de la responsabilidad del Estado por hechos internacionalmente ilícitos y su aprobación del proyecto de artículos, así como de un comentario detallado acerca del tema;

2. Expresa su agradecimiento a la Comisión de Derecho Internacional por su contribución continua a la codificación y el desarrollo progresivo del derecho internacional;

3. Toma nota de los artículos sobre la responsabilidad del Estado por hechos internacionalmente ilícitos, presentados por la Comisión de Derecho Internacional, cuyo 
texto figura en el anexo de la presente resolución, y los señala a la atención de los gobiernos, sin perjuicio de la cuestión de su futura aprobación o de otro tipo de medida, según corresponda;

4. Decide incluir en el programa provisional de su quincuagésimo noveno período de sesiones un tema titulado "Responsabilidad del Estado por hechos internacionalmente ilícitos. (ONU, 2001, p. 1)

La Asamblea General no se pronunció sobre el destino del proyecto o sobre si se realizaría una conferencia internacional cuyo objetivo sería crear una convención sobre la responsabilidad internacional de los Estados por el hecho ilícito internacional, sino que reposó en un grupo de trabajo de la VI Comisión de la Asamblea hasta nuestros días. A pesar de esto último, este proyecto tiene una importancia muy relevante en la vida jurídica internacional, aunque no esté contenido en un tratado formal, de suerte que se considera por algunos doctrinantes que las normas de carácter consuetudinario ordenadas y sistematizadas en un texto escrito:

Acrece su certidumbre y favorece:

1) su irradiación sobre la jurisprudencia internacional - prueba de ello son los pronunciamientos judiciales que lo citan (TPIY, Nikolic, 2002, y, sobre todo, CIJ, Muro, 2004; Pasteras en el río Uruguay, 2010); y

2) su influjo potencial sobre los regímenes internacionales que, a título de lex specialis, contienen reglas sobre la responsabilidad por la infracción de sus disposiciones. (Remiro et al., 2010, p. 405)

En el acápite siguiente se expondrán los artículos más relevantes para el objetivo de este artículo, en el sentido en que configuran las normas consuetudinarias aplicables a un evento de responsabilidad internacional de un Estado, sin desconocer los fallos citados que son relevantes para las posibles posiciones argumentativas que se podrían esgrimir.

\section{Elementos de la responsabilidad internacional por el hecho ilícito en el caso del tratado constitutivo de la Organización Mundial de la Salud}

Antes de 2001, año en el que se sistematizaron las normas consuetudinarias en materia de responsabilidad internacional por el hecho ilícito, autores muy destacados como Verdross sostenían que, según el Derecho Internacional común, "un sujeto de D. I. (sic) que infringe una norma jurídico internacional común o particular, es responsable con respecto al sujeto perjudicado" (Verdross, 1963, p. 297). Este mismo autor expresaba que la negación de este principio "implicaría la destrucción del D. I. (sic), puesto que el no admitir la responsabilidad consiguiente a un entuerto suprimiría el deber de los Estados de comportarse según el D.I. (sic)" (Verdross, 1963, p. 297).

En ese entonces, es decir antes de 2001, la doctrina reconocía unos elementos constitutivos de la responsabilidad internacional. Un primer elemento consistía en la existencia de un acto u omisión que viole una obligación establecida por una norma de Derecho Internacional vigente entre el Estado responsable del acto u omisión y el Estado perjudicado; un segundo elemento en que el acto ilícito debía ser imputable al Estado como persona jurídica; y un tercer elemento en que debería haberse producido un perjuicio o un daño como consecuencia del acto ilícito (Jiménez de Aréchaga, 1980). Respecto de este tercer elemento, algunos autores aclaraban que no era necesario que el daño o perjuicio tuviere el carácter de daño económico, porque es posible que dicho 
daño o perjuicio no comportara una mengua en el patrimonio del Estado que ostenta el rol de víctima, como ocurre con las ofensas al honor del Estado (Verdross, 1963).

En el "Proyecto de artículos sobre responsabilidad de los Estados por hechos internacionalmente ilícitos" de la Comisión de Derecho Internacional, el principio de la Responsabilidad del Estado por sus hechos internacionalmente ilícitos se encuentra consagrado en el artículo 1, según el cual "Todo hecho internacionalmente ilícito del Estado genera su responsabilidad internacional" (CDI, 2001), y en el artículo 2 del mismo proyecto se establecen los elementos del hecho internacionalmente ilícito del Estado, que refleja el desarrollo jurisprudencial en la materia (Crawford, 2012). En dicho artículo 2, se establece que:

Hay hecho internacionalmente ilícito del Estado cuando un comportamiento consistente en una acción u omisión:

a) Es atribuible al Estado según el derecho internacional; y 2001)

b) Constituye una violación de una obligación internacional del Estado. (CDI,

Estos ítems han sido considerados como los elementos subjetivo y objetivo del hecho generador de responsabilidad internacional (Dupuy y Kerbat, 2014). Respecto del elemento subjetivo, valga expresar la atribución del acto u omisión a un Estado, James Crawford, quien fue el último relator del proyecto de Responsabilidad del Estado por sus hechos internacionalmente ilícitos de la Comisión de Derecho Internacional, expresa que no todo aquel que está asociado con un Estado puede actuar en nombre de dicho Estado (Crawford, 2002). Es por esto que los artículos 4 y 11 de la Responsabilidad del Estado por sus hechos internacionalmente ilícitos se listan los órganos estatales, individuos privados y grupos insurrectos o rebeldes. Desde luego, respecto de este tema es muy relevante lo expresado en líneas anteriores sobre el elemento "control" de la actividad por parte del Estado, pues si bien hay desavenencias sobre éste ${ }^{4}$, hay casos como el citado "Rainbow Warrior" en el cual fue definitivo.

Respecto del elemento objetivo, valga expresar que la violación de una obligación internacional del Estado conlleva una reflexión necesaria que se cristaliza en la siguiente pregunta: ¿es el mero hecho de que el Estado ha cometido un acto internacionalmente ilícito suficiente para establecer solo la responsabilidad, o es necesario también establecer la culpa? Para dar una respuesta, el Derecho Internacional Consuetudinario reconoce dos teorías para hacer responsable a un Estado por el hecho internacionalmente ilícito. La primera, que puede ser descrita como la regla de la responsabilidad objetiva (strict liability), establece que el Estado es responsable por el hecho ilícito internacional sin considerar su intención. No importa si el Estado es negligente, actúa de buena fe o el contenido del acto es inmaterial (como la deshonra), lo importante es que el hecho o acto internacionalmente ilícito ocurrió. La segunda teoría establece la responsabilidad subjetiva, por la cual un Estado es responsable por un hecho ilícito solo si hay dolo o culpa de su parte (Abass, 2014).

En el Proyecto de Responsabilidad del Estado por sus hechos internacionalmente ilícitos de la Comisión de Derecho Internacional no hay una disposición en favor o en contra de alguna de las teorías antes citadas, y para algunos lo más práctico es que se aplique una u otra según sea el caso, tal y como sugieren Crawford y Olleson (2010), para quienes es ilusorio buscar una sola regla dominante, porque para ellos todo depende del contexto específico y del contenido e interpretación de la obligación que se dice haber violentado. 
Para otros autores, como Dupuy y Kerbat (2014), debe prevalecer la responsabilidad objetiva, a razón de que dicho hecho ilícito internacional no se basa en una falta sino una ausencia de derecho. La economía generada al evitar la búsqueda de móviles del acto o las intenciones del o de los autores facilita la labor jurídica de la víctima, pues las pruebas deberán un encuadrar de manera objetiva entre el comportamiento real del Estado y su el contenido de la obligación jurídica. En ese mismo sentido, tras una revisión profunda de la doctrina y la práctica aplicable, Shaw apoya la prevalencia de la teoría de la responsabilidad objetiva, dejando en claro que el problema de la intención debe distinguirse del problema de la causalidad, pero haciendo la salvedad que los comentaristas del Proyecto de Responsabilidad del Estado por sus hechos internacionalmente ilícitos de la CDI (ONU, 2008) expresan que la atribución a uno u otro régimen de ser valorado según las circunstancias (Shaw, 2011). En suma, hay una tendencia que favorece la responsabilidad objetiva, pero es un debate aún abierto que depende de las circunstancias.

\section{Sobre la Organización Mundial de la Salud y su Reglamento}

Creada con el objeto de establecer una organización sanitaria autónoma e internacional (Organización Mundial de la Salud [OMS], 2008), el día 22 de julio de 1946 se adoptó el tratado constitutivo de la OMS, el cual entró en vigor el 07 de abril de 1948 (OMS, 2006). Adicionalmente, con la entrada en vigor del acuerdo de vinculación con la ONU, la OMS se convirtió formalmente en un organismo especializado de aquella el 10 de julio de 1948.

En cuanto a su estructura, según del artículo noveno del tratado constitutivo de la OMS, el organismo está compuesto por: (i) la Asamblea Mundial de la Salud, llamada también Asamblea de la Salud, integrada por los representantes de todos los Estados miembros de la Organización; (ii) el Consejo Ejecutivo; y (iii) la Secretaría (OMS, 1946/2006).

Por su parte, el artículo vigésimo primero de dicho tratado señala que la Asamblea de la Salud tiene autoridad para adoptar reglamentos, estableciéndose la fuerza vinculante de ellos para los Estados Miembros de la organización. Dichos reglamentos pueden versar sobre materias relativas a:

a) requisitos sanitarios y de cuarentena y otros procedimientos destinados a prevenir la propagación internacional de enfermedades; pública;

b) nomenclaturas de enfermedades, causas de muerte y prácticas de salubridad

c) normas uniformes sobre procedimientos de diagnóstico de uso internacional;

d) normas uniformes sobre la seguridad, pureza y potencia de productos biológicos, farmacéuticos y similares de comercio internacional;

e) propaganda y rotulación de productos biológicos, farmacéuticos y similares de comercio internacional. (OMS, 1946/2006, capítulo V)

Seguidamente, el artículo vigésimo segundo versa sobre la vinculación de dichas reglamentaciones con los Estados Parte, señalando al efecto:

Estas reglamentaciones entrarán en vigor para todos los Miembros después de que se haya dado el debido aviso de su adopción por la Asamblea de la Salud, excepto 
para aquellos Miembros que comuniquen al Director General que las rechazan o hacen reservas dentro del periodo fijado en el aviso (OMS, 1946/2006, capítulo V).

En virtud de dicha facultad normativa, en la Quincuagésima octava Asamblea Mundial de la Salud desarrollada el año 2005, se adoptó el Reglamento Sanitario Internacional (RSI), cuya entrada en vigor fue el 15 de junio de 2007 (OMS, 2005/2016), el cual:

“...tiene por objeto prevenir la propagación internacional de enfermedades, proteger contra esa propagación, controlarla y darle una respuesta, evitando al mismo tiempo las interferencias innecesarias con el tráfico y el comercio internacionales. EI RSI (2005) también está concebido para reducir el riesgo de propagación de enfermedades en aeropuertos, puertos y pasos fronterizos terrestres internacionales" (OMS, s.f.).

Para el análisis a realizar en este artículo cobran vital relevancia las obligaciones que el RSI impone a los 194 países para los cuales resulta vinculante.

Al respecto, el artículo sexto del RSI establece que los Estados Parte deben evaluar los eventos que se produzcan en su territorio y que puedan constituir una emergencia de salud pública de importancia internacional. Adicionalmente, impone la obligación de notificar a la OMS por el medio de comunicación más eficiente que disponga del acaecimiento de un evento de estas características y de todas las medidas sanitarias ejecutadas como respuesta. Dicha comunicación de efectuarse a través del Centro Nacional de Enlace para el RSI, en un plazo máximo de veinticuatro horas desde que se haya evaluado la información. A su vez, el numeral segundo del mismo artículo impone la obligación de seguir comunicando a la OMS la información oportuna, exacta y suficientemente detallada sobre la salud pública de que disponga relativa al evento notificado, así como de las dificultades surgidas y el apoyo necesario en la respuesta a la eventual emergencia de salud pública de importancia internacional (OMS, 2005/2016).

Seguidamente, el artículo séptimo impone la obligación a los Estados Parte de facilitar a la OMS toda la información relativa a la salud pública cuando tenga pruebas que se ha producido un evento imprevisto o inusual, con independencia de su origen o procedencia, que pudiese constituir una emergencia de salud pública de importancia internacional, aplicándose en su totalidad las disposiciones previstas en el artículo 6 (OMS, 2005/2016).

De esta forma, y en atención a lo analizado en el acápite anterior, incurrirá en responsabilidad internacional por hecho ilícito todo Estado Parte vinculado al RSI que incumpla las obligaciones que éste impone.

\section{Sobre el origen y la propagación del COVID-19}

Según la información del sitio oficial de la OMS, el 31 de diciembre de 2019, la oficina del organismo ubicado en la República Popular de China detectó una "declaración de la Comisión Municipal de Salud de Wuhan para los medios de comunicación publicada en su sitio web en la que se mencionan casos de una 'neumonía vírica' en Wuhan" (OMS, 2020). Asimismo, expone que dicha oficina transmitió dicha declaración, en conjunto con la respectiva traducción, al centro de enlace para el RSI de la Oficina Regional de la OMS para el Pacífico Occidental.

Se señala que, paralelamente, la plataforma de la OMS de inteligencia epidémica obtuvo "un informe para los medios de comunicación en ProMED (un programa de la 
Sociedad Internacional para las Enfermedades Infecciosas) sobre el mismo conglomerado de casos de una 'neumonía de causa desconocida' en Wuhan" (OMS, 2020).

Por lo anterior, el 01 de enero de 2020, la OMS solicitó a las autoridades chinas que otorgaran información respecto a la noticia que habían obtenido del conglomerado de casos, la cual fue reiterada por el representante de la OMS en dicho país al día siguiente (OMS, 2020). Paralelamente, los canales de televisión chinos informaban que ocho médicos de la ciudad de Wuhan fueron amonestados por considerarse que difundieron rumores falsos al comparar el nuevo virus con el SARS-CoV-2 de inicio de siglo (El Español, 2020).

El día 03 de enero del año en curso, la OMS publicó que recibió información oficial por parte de China sobre el conglomerado de casos de neumonía vírica de origen desconocido detectada en Wuhan, capital de Hubei, China (OMS, 2020). Dos días después, la Comisión de Salud Municipal de Wuhan informó que inició una investigación retrospectiva sobre el brote, pues los casos de neumonía no correspondían a los virus SARS-CoV-2 ni MERS (CNN, 2020). Posteriormente, el 09 de enero de 2020, la OMS comunicó que las autoridades chinas habían determinado que el brote fue provocado por un nuevo virus denominado 2019-nCoV (OMS, 2020), mientras que en China se producía la primera muerte a consecuencia del virus (CNN, 2020).

No existe consenso en la comunidad internacional sobre la fecha en que se habría iniciado la pandemia. Según las autoridades de salud de la ciudad de Wuhan, los primeros casos ocurrieron entre los días 12 y 29 de diciembre del año 2019 (CNN Español, 2020). Sin embargo, según la investigación realizada por South China Morning Post, el primer contagiado por el nuevo coronavirus data del 17 de noviembre de 2019 (Ma, 2020). Por su parte, en la revista médica The Lancet se publicó un estudio realizado por médicos chinos del Hospital Jinyintan en Wuhan, en el cual se sostiene que el primer diagnóstico del nuevo coronavirus fue el día 01 de diciembre de 2019 (Press y Jung, 2020).

De acuerdo con la declaración emitida por Zhang Jixian, médico del Hospital Provincial de Medicina China y Occidental Integrada de Hubei, ya el 27 de diciembre de 2019 había advertido a las autoridades nacionales que se trataba de un nuevo coronavirus (Ma, 2020). Sin embargo, en una entrevista realizada por el canal del Estado "Televisión Central de China", el 10 de enero de 2020, Wang Guangfa, experto gubernamental en enfermedades respiratorias, declaró que la neumonía de Wuhan estaba bajo control y se trataba de una condición leve (Ma, 2020). Dos días después de estas declaraciones, la OMS recibió por parte de la Comisión Nacional de Salud China las secuencias genéticas del nuevo coronavirus (OMS, 2020).

Sin embargo, el mapa genético había sido decodificado parcialmente con dos semanas de anticipación y de manera completa con más de una de anticipación por tres laboratorios del gobierno, los cuales se vieron presionados a darlo a conocer, a razón de la publicación de la secuencia por otro laboratorio el sitio web virological.org y la nota en el Wall Street Journal que informaba que los científicos habían descubierto un coronavirus nuevo en las muestras de los pacientes de Wuhan (The Associated Press, 2020). Adicionalmente, Yuen Kwok-yung, investigador de la Universidad de Hong Kong, aseguró haber informado al gobierno chino de la sospecha de transmisión humana del virus el 12 de enero del año en curso, pero ella se dio a conocer por las autoridades una semana después (BBC News Brasil, 2020). 
A pesar del conocimiento de esta información, el 18 de enero del 2020 se realizó en la ciudad de Wuhan un espectáculo al que asistieron más de 40.000 familias, a fin de competir por el récord mundial de más platos servidos en un evento (Ma, 2020). Posteriormente, en una entrevista el 27 de enero, el alcalde de Wuhan, Zhou Xianwang, asumió que la información debió haberse divulgado con mayor rapidez (Raulaha, 2020).

El 22 de enero de 2020, la misión de la OMS en China declaró que con la información obtenida quedaba demostrada la trasmisión del virus entre seres humanos en la ciudad de Wuhan (ONU, 2020), mientras que las autoridades chinas confirmaban al menos 547 casos de contagiados en China continental (CNN Español, 2020).

Ante este escenario, las autoridades chinas decretaron el cierre total al tráfico público, incluyendo todos los vuelos en Wuhan y en Huanggang desde el 23 de enero. Adicionalmente, se adoptaron medidas tales como el suministro de mascarillas, la recomendación a personas sintomáticas de aislamiento domiciliario, el cierre de locales de atención al público y actividades escolares en un total de 14 ciudades (Departamento de Seguridad Nacional de España, 2020). Así, al día 29 de enero, todas las ciudades de la provincia de Hubei estaban selladas (BBC News Mundo, 2020).

Al día siguiente, en atención a los 9.700 casos confirmados en China y 106 casos confirmados en otros países, la OMS declaró al brote del nuevo coronavirus como una emergencia de salud pública de importancia internacional (ESPII), en cumplimiento de la recomendación del Comité de Emergencia del Reglamento Sanitario Internacional (Organización Panamericana de la Salud [OPS], 2020). Dos días después, se registró la primera muerte a causa del nuevo virus fuera de China continental (CNN, 2020).

Finalmente, el 11 de marzo de 2020, el director general de la OMS informó que la COVID-19 (denominado así desde el 11 de febrero de 2020) era considerado una pandemia, en atención a la existencia de más de 118.000 casos de contagiados en 114 países y 4291 muertes a causa de éste (Adhanom, 2020).

\section{6. ¿Es posible atribuir responsabilidad a China?}

Con este contexto teórico e histórico, procederemos a continuación a verificar si los dos elementos, el subjetivo y el objetivo, contenidos en el artículo 2 del Proyecto de Responsabilidad del Estado por sus hechos internacionalmente ilícitos de la Comisión de Derecho Internacional, están presentes en el caso de la COVID-19 respecto del tratado constitutivo de la OMS.

\subsection{Elemento objetivo}

Para realizar el análisis de la configuración del elemento objetivo, cabe hacer presente que China es Estado Miembro de la OMS, por ende, no solo el tratado constitutivo le es exigible, sino que también las reglamentaciones que dicte la Asamblea Mundial de la Salud en el ejercicio de sus funciones.

De esta forma, al analizar el actuar de China al inicio de la pandemia (cualquiera sea la fecha que se escoja de las ya expuestas), es posible concluir que incumplió o cumplió imperfectamente las obligaciones que impone el RSI. Así, sea que se considere el artículo sexto o séptimo del referido reglamento, el Estado de China no cumplió con entregar la información de la forma más eficiente del brote del nuevo virus a la OMS dentro del plazo máximo de 24 horas desde que las autoridades locales tomaron conocimiento del aumento explosivo de los contagiados por éste, como impone la norma. 
Además, posterior a la notificación tardía a la OMS, incumplió con la obligación de seguir entregando la información sobre la salud pública de la cual disponía de manera oportuna y detallada, pues como se evidenció, existió retraso de semanas en la comunicación de antecedentes tan importantes como los datos genéticos completos del nuevo virus, siendo dados a conocer por medios de comunicación de otros países antes que se recibiera por la organización sanitaria.

En consecuencia, el Estado de China incumplió con las disposiciones del RSI y, consecuencialmente, con los artículos 21 y 22 de la Constitución de la Organización Mundial de la Salud a los cuales se encuentra obligado.

\subsection{Elemento subjetivo}

En ese orden de ideas, la demora y parcialidad en la entrega de la información corresponden a una omisión intencional de China, pues no existe en el relato de los hechos causa alguna que justifique el actuar de las autoridades al inicio del brote del virus y, menos aún, alguna que lo haga respecto a la conducta sostenida durante las semanas posteriores a la notificación efectuada a la OMS.

Lo anterior es con independencia que se considere el actuar de las autoridades locales de Wuhan o las autoridades a nivel nacional, en virtud de lo establecido en el "Proyecto de artículos sobre responsabilidad de los Estados por hechos internacionalmente ilícitos", pues, en ambos casos, dicho proceder es atribuible a China, posición que se refuerza si se analizan los fallos citados sobre el control de la actividad que el mencionado Estado tenía de la situación.

\section{El proceso de solución pacífica de la controversia}

Como es sabido, la idea de solucionar pacíficamente las controversias internacionales tiene antecedentes claros en la primera Conferencia de La Haya (1899), de la cual emana el primer tratado colectivo para la solución pacífica de conflictos internacionales, que se renueva en la segunda Conferencia de La Haya de 1907 (Verdross, 1963). Bajo la lógica posterior del Derecho Internacional Público posterior a la Segunda Guerra Mundial, el artículo segundo numeral 3 de la Carta de Naciones Unidas establece dicho principio bajo los siguientes términos: "Los Miembros de la Organización arreglarán sus controversias internacionales por medios pacíficos de tal manera que no se pongan en peligro ni la paz y la seguridad internacionales ni la justicia" (ONU, 1945, capítulo I).

En plena concordancia con el principio de solución pacífica de controversias contenido en el precepto legal anteriormente citado, el artículo septuagésimo quinto del tratado constitutivo de la OMS regula los mecanismos de dicha solución pacífica de controversias de la siguiente manera:

Toda divergencia o disputa respecto a la interpretación o aplicación de esta Constitución que no sea resuelta por negociaciones o por la Asamblea de la Salud será sometida a la Corte Internacional de Justicia, de conformidad con el Estatuto de la Corte, a menos que las partes interesadas acuerden otro medio de solucionarla. (OMS, 1946/2006, capítulo XVIII)

El artículo anterior genera los siguientes cuestionamientos a considerar para la solución efectiva del caso: ¿Cómo determinar si hay o no una divergencia o disputa? ¿Cuál es el alcance de las negociaciones? ¿Hasta dónde deben llegar las negociaciones? ¿Puede la Asamblea de la Salud solucionar la controversia? ¿Cómo 
hacer efectiva la responsabilidad internacional? A continuación, se dará respuesta de cada una de estas preguntas.

Tradicionalmente, cuando se trata de definir en el Derecho Internacional Público el concepto o alcance de una controversia, se acude al clásico caso de las concesiones Mavrommatis en Jerusalem, en el cual la Corte Permanente de Justicia Internacional estableció que "una diferencia es un desacuerdo sobre un punto de derecho o de hecho, una contradicción de tesis jurídicas o de intereses entre dos personas" (Grecia c. Reino Unido, 1924, p. 11). En este caso, según lo analizado en el acápite anterior, habría una controversia en la medida en que al menos dos partes estarían en desacuerdo en la aplicación de ciertos preceptos de la Constitución de la OMS y/o sus reglamentos. Una de las partes sería China, y la otra u otras los Estados que eventualmente le reclamarían la responsabilidad por el hecho ilícito internacional.

A lo anterior se sumaría lo fijado en el Caso relativo al África Sudoccidental por parte de la $\mathrm{ClJ}$, en el cual la mencionada ClJ afirmó que en una controversia "debe demostrarse que la afirmación de una de las partes se opone positivamente a la otra" (Etiopía c. Sudáfrica y Liberia c. Sudáfrica, 1962, p. 7). Bajo la argumentación anterior, habría pocas dudas respecto de la presencia de una controversia que activaría la necesidad de acudir a los métodos de solución pacífica, que el artículo septuagésimo quinto de la Constitución de la OMS establece con una progresión: primero las negociaciones, después la actuación de la Asamblea de la Salud y, posteriormente, si las partes no resuelven otro método, el recurso ante la ClJ.

En cuanto a la negociación entre las partes, la regla general que ha establecido la CIJ es que no son prerrequisito para que la propia CIJ pueda ejercer su jurisdicción, como consta en los casos Plataforma continental del mar Egeo (Etiopía c. Sudáfrica y Liberia c. Sudáfrica, 1978), Límite terrestre y marítimo entre Camerún y Nigeria (Camerún c. Nigeria, 1998). Sin embargo, el texto del artículo septuagésimo quinto de la Constitución de la OMS impone a las negociaciones como requisito previo a los demás métodos que el propio artículo indica. En dichas negociaciones deberían estar presentes China, como presunto epicentro del virus, y algunos de los Estados que reclaman la responsabilidad, como por ejemplo Australia, que ha sido enfática en buscar mecanismos como investigaciones internacionales (Mercer, 2020).

En este punto surgen dos preguntas, que previamente se esbozaron: ¿Cuál es el alcance de las negociaciones? ¿Hasta dónde deben llegar éstas? La jurisprudencia de la ClJ confiere una gran ayuda para resolver esas preguntas. En primer lugar, en cuanto al alcance, las negociaciones deben reflejar el objeto de la disputa, que debe concernir a las obligaciones sustanciales contenidas en el tratado en cuestión, como se estableció en el caso relativo a la aplicación de la Convención Internacional sobre la eliminación de todas las formas de discriminación racial (Georgia c. Federación Rusa, 2011). En segundo lugar, las negociaciones deben darse "en la medida permitida por las circunstancias del caso", como lo estableció en el caso relativo al Derecho de paso por territorio de la India (Portugal c. India, 1957).

Entonces, bajo los criterios anteriores, la negociación o las negociaciones deben darse en el marco de las obligaciones sustanciales del tratado hasta que sean posibles dadas las circunstancias, de manera que, si no se logra solucionar la controversia por esta vía, procederá acudir a la Asamblea de la Salud. En cuanto a la aptitud de la Asamblea de la Salud para resolver la controversia en caso que no pueda ser solucionada por medio de negociaciones, hay varias dudas, especialmente porque dentro de las facultades contenidas en el artículo décimo octavo de la Constitución de la $\mathrm{OMS}^{5}$, no hay elementos fuertes como para lograr zanjar una controversia, salvo que 
se pudiera enmarcar en el amplio texto del literal $\mathrm{m}$ ) del mencionado artículo, en virtud del cual la Asamblea de la Salud puede "emprender cualquier acción apropiada para el adelanto de la finalidad de la Organización” (OMS, 1946/2006, capítulo V).

Si esas acciones que pudiere emprender la Asamblea de la Salud no fueran efectivas, se genera la siguiente pregunta: ¿Cómo hacer efectiva la Responsabilidad Internacional ante la ClJ? La respuesta a esta pregunta genera a lo menos tres aspectos cuyo análisis desbordaría el espacio fijado para el desarrollo de este artículo, por la profundidad para establecer fehacientemente los mismos. Dichos aspectos serían el tema probatorio de la relación de causalidad respecto de lo acaecido en otros Estados, pues si bien China pudo haber incumplido las normas comentadas anteriormente, entre otras, las medidas sanitarias que debieron o pudieron tomar otros Estados para evitar la propagación también se deben tener en cuenta, pues si bien son aspectos jurídicos propios de cada Estado que conllevan su responsabilidad de conformidad en el Derecho interno (fallado servicio u otra figura análoga), afectan aspectos internacionales ${ }^{6}$.

En efecto, lo precedentemente expresado tiene efectos en a lo menos dos aspectos, la cuantía de la indemnización, quede por sí no es fácil de establecer, y menos aún dado el impacto económico que han traído medidas de restricción de la movilidad de las personas, como cuarentenas y confinamientos. Además, dado que están involucrados varios actores en la expansión de la sindemia ${ }^{7}$, la ClJ tendría que revisar si opera el principio "Monetary Gold Rule"8, que es un principio establecido en la Sentencia de la CIJ (1954) en el Caso del Oro Amonedado Retirado de Roma en 1943, según el cual la CIJ no debería ejercer su jurisdicción para fallar en un caso entre dos partes, cuando los intereses legales de un tercero no solo serían afectados por la decisión, sino que, además, constituiría el objeto mismo de la decisión. La ClJ, por decisión unánime, sentenció que "la jurisdicción conferida por el acuerdo común entre Francia, el Reino Unido, los Estados Unidos de América e Italia no le autoriza, en ausencia del consentimiento de Albania, a pronunciarse sobre la primera comunicación en la solicitud del Gobierno italiano" (Italia c. Francia, Reino Unido de Gran Bretaña e Irlanda del Norte y Estados Unidos de América, 1954).

A lo anterior se adiciona otra dificultad en el orden procesal, consistente, grosso modo, en que los mecanismos precedentemente expuestos son válidos en la medida en que las reclamaciones tengan como origen la Constitución de la OMS, pero si las reclamaciones de responsabilidad internacional provienen de controversias por la interpretación o aplicación del Reglamento Sanitario Internacional, que también son aplicables al caso como se revisó en su momento, los mecanismos de solución de controversias pueden diferir entre ambos instrumentos internacionales. En efecto, el artículo 56 del $\mathrm{RSI}^{9}$ establece los mecanismos de solución de controversias en caso y establece una estructura diferente para esos fines.

El primer mecanismo de solución de controversias del RSI es la negociación, en lo cual hay coincidencia con la Constitución de la OMS, y, por ello, no habría mayor dificultad. La complejidad aparece si el caso no se logra finiquitar por medio de negociaciones, porque el segundo y tercer mecanismos de solución de controversias del RSI discrepan con los de la Constitución OMS. El segundo mecanismo corresponde a la mediación o buenos oficios que pueda hacer el Director General de la OMS, y el tercer mecanismo, en caso de no solucionarse mediante la intervención del mencionado Director, es el Arbitraje, con lo cual habría una diferencia profunda con el Constitución OMS que establece el recurso a la CIJ. En razón de la presencia de estas dos fórmulas para que un tercero solucione la controversia, los Estados que pretendan reclamar la responsabilidad internacional deberán ser muy acuciosos para seleccionar las normas infringidas porque si no se logra una adecuada negociación, el caso podría quedar 
entrampado procesalmente por la indefinición del mecanismo al cual acudir, si se alude a normas de la Constitución OMS se debería acudir a la ClJs y si se alude a normas del RSI, se debe acudir a Arbitraje.

\section{Conclusiones}

En el caso de la responsabilidad por el hecho ilícito con ocasión de COVID-19, los elementos que constituyen la misma de conformidad con lo establecido en el proyecto de la Comisión de Derecho Internacional son claramente identificables, y habría diversos fallos judiciales que apoyarían dicha responsabilidad, ya sea por ser considerada objetiva, o por el control de la situación que estaba a cargo de China. Sin embargo, los procedimientos de solución pacífica de controversias establecidos en la Constitución de la OMS harán que, en caso de invocarse, éstos sean dilatados en el tiempo, más si se incluye normas del RSI. Es de esperar que las negociaciones por sí mismas lograrán una solución, pero en la práctica los factores de poder real no auguran un resultado efectivo, como tampoco lo hace la posible intervención de la Asamblea de la Salud.

El recurso judicial ante la CIJ dependerá de múltiples factores, jurídicos y políticos, que harían un juicio muy interesante, y en el cual no se debatirían únicamente las normas de la OMS, sino que podrían invocarse múltiples tratados que podrían ser efectivos para dilucidar el caso, con lo cual la complejidad del mismo aumentaría sin lugar a dudas. Uno de los puntos más interesantes sería el de la participación de los actores involucrados, pues por el alcance global de la pandemia -o sindemia, como se califica por algunos-, casi todos los Estados del mundo estarían interesados en participar en un juicio, con lo cual se plantearía un verdadero desafío al artículo septuagésimo segundo del Estatuto de la Corte Internacional de Justicia ${ }^{10}$. Si se acude a los mecanismos del RSI, se puede prever dificultades procesales para poder constituir un Tribunal Arbitral en los términos fijados por el artículo 56 del RSI.

\footnotetext{
${ }^{1}$ Podrían estudiarse una buena cantidad de fuentes del Derecho Internacional Público para hallar la responsabilidad internacional por el hecho ilícito, pero para efectos de cumplir con la extensión permitida de cada aporte, este artículo se ceñirá a la normatividad más relevante de la Organización Mundial de la Salud.

2 Esta aseveración fue realizada en una primera instancia por el Juez Huber, quien expresó "la responsabilidad es el corolario necesario de un derecho. Todos los derechos de un carácter internacional envuelven responsabilidad internacional. La Responsabilidad deviene en un deber de hacer una reparación si la obligación en cuestión no se cumple" (traducción libre, realizada por los autores de este artículo). Gran Bretaña v. España (1924). The Spanish protectorate over Morocco was established by a Spanish-Moroccan treaty of 27 November 1912, p. 641. https://www.oxfordreference.com/view/10.1093/oi/authority.20110803100521331

Doctrinalmente, también se puede encontrar esta aseveración en autores como: Daillier, P., Forteau, M., Pellet, A. (2009). Droit International Public. L.G.D.J.

${ }^{3}$ Sobre el tema del control no hay una última palabra, pues si bien en el caso Nicaragua y en el caso Tadic [(11 de noviembre de 1999). Tribunal Penal Internacional para la Antigua Yugoslavia. https://www.icty.org/x/cases/tadic/tjug/en/tad-tsj991111e.pdf] el control sobre las actividades era suficiente para generar la responsabilidad del Estado, la CIJ no consideró el control para establecer la Responsabilidad Internacional en el Caso Relativo a la Aplicación de la Convención sobre la Prevención y Sanción del Delito de Genocidio [Bosnia y Herzegovina c. Yugoslavia (Serbia y Montenegro)]. (08 de abril de 1983). Corte Internacional de Justicia. https://www.icjcij.org/files/case-related/91/091-20070226-JUD-01-00-EN.pdf].

${ }^{4}$ Ver Reino Unido, Francia, Italia y Japón c. Alemania (17 de agosto de 1923). Corte Permanente de Justicia Internacional. https://www.icj-cij.org/files/permanent-court-of-internationaljustice/serie_A/A_01/03_Wimbledon_Arret_08_1923.pdf

${ }^{5}$ Las funciones de la Asamblea de la Salud serán:
} 
a) determinar la política de la Organización; b) nombrar los Miembros que tengan derecho a designar una persona para el Consejo; c) nombrar el Director General; d) estudiar y aprobar los informes y actividades del Consejo y del Director General y dar instrucciones al Consejo sobre los asuntos en los cuales se considere conveniente acción, estudio, investigación o informe; e) establecer los comités que considere necesarios para el trabajo de la Organización; f) vigilar la política financiera de la Organización y estudiar y aprobar su presupuesto; g) dar instrucciones al Consejo y al Director General para llamar la atención de los Miembros y de las organizaciones internacionales, gubernamentales o no, sobre cualquier asunto relacionado con la salubridad que estime conveniente la Asamblea de la Salud; h) invitar a cualquier organización internacional o nacional, gubernamental o no gubernamental, que tenga responsabilidades relacionadas con las de la Organización, a que nombre representantes para participar, sin derecho a voto, en sus reuniones o en las de comités y conferencias celebradas bajo sus auspicios, en las condiciones que prescriba la Asamblea de la Salud; pero en el caso de organizaciones nacionales, las invitaciones se harán solamente con el consentimiento del Gobierno interesado; i) considerar las recomendaciones sobre salubridad hechas por la Asamblea General, el Consejo Económico y Social, el Consejo de Seguridad o el Consejo de Administración Fiduciaria de las Naciones Unidas, e informarles sobre las medidas tomadas por la Organización para poner en práctica tales recomendaciones; j) informar al Consejo Económico y Social, conforme a los acuerdos que se concierten entre la Organización y las Naciones Unidas; k) promover y realizar investigaciones en el campo de la salubridad, mediante el personal de la Organización, por el establecimiento de sus propias instituciones, o en cooperación con instituciones oficiales o no oficiales de cualquier Miembro, con el consentimiento de su gobierno; I) establecer otras instituciones que considere conveniente; $\mathrm{m}$ ) emprender cualquier acción apropiada para el adelanto de la finalidad de la Organización.

${ }^{6}$ Sobre este aspecto puede profundizarse: Garrido Muñoz, A. (2020). Hablemos de Derecho Internacional [Podcast]. https://open.spotify.com/show/7CBoPJDOuU2MXle0Aca1dc

7 Sobre el alcance de este término que es más amplio que el de pandemia, puede consultarse: Plitt, L. (2020). El covid-19 no es una pandemia: Ios científicos que creen que el coronavirus es una sindemia (y qué significa esto para su tratamiento). https://www.bbc.com/mundo/noticias54386816

8 Para profundizar sobre este principio, puede consultarse: Samara, C. (2018). The Monetary Gold Principle and the Member States Responsibility. https://ssrn.com/abstract=3450156

${ }^{9}$ Artículo 56 Solución de controversias.

${ }^{9}$ Artículo 62 del Estatuto de la Corte Internacional de Justicia: "1. Si un Estado considerare que tiene un interés de orden jurídico que puede ser afectado por la decisión del litigio, podrá pedir a la Corte que le permita intervenir".

2. La Corte decidirá con respecto a dicha petición."

1. En caso de que se produzca una controversia entre dos o más Estados Partes acerca de la interpretación o la aplicación del presente Reglamento, los Estados Partes en cuestión tratarán de resolverla en primer lugar negociando entre ellos o de cualquier otra forma pacífica que elijan, incluidos los buenos oficios, la mediación o la conciliación. De no llegar a un entendimiento, las partes en disputa no estarán eximidas de seguir tratando de resolver la controversia.

2. En caso de que la controversia no se solucione por los medios descritos en el párrafo 1 del presente artículo, los Estados Partes en cuestión podrán acordar que se someta al Director General, quien hará todo lo posible por resolverla.

3. Todo Estado Parte podrá en cualquier momento declarar por escrito al Director General que reconoce como obligatorio el arbitraje para la solución de todas las controversias relativas a la interpretación o la aplicación del presente Reglamento en las que sea parte, o de una controversia concreta frente a otro Estado Parte que acepte la misma obligación. El arbitraje se realizará de acuerdo con el Reglamento Facultativo de la Corte Permanente de Arbitraje para el Arbitraje de Controversias entre Dos Estados vigente en el momento en que se formule la petición de arbitraje. Los Estados Partes que hayan acordado reconocer como obligatorio el arbitraje aceptarán el laudo arbitral con carácter vinculante y definitivo. El Director General informará a la Asamblea de la Salud acerca de dicha medida, según proceda.

4. Ninguna disposición del presente Reglamento menoscabará los derechos de que gocen los Estados Partes en virtud de un acuerdo internacional en el que puedan ser partes a recurrir a los mecanismos de solución de controversias de otras organizaciones intergubernamentales 0 establecidos en virtud de un acuerdo internacional. 
5. En caso de que se produzca una controversia entre la OMS y uno o más Estados Partes respecto a la interpretación o aplicación del presente Reglamento, la cuestión será sometida a la Asamblea de la Salud.

\section{Referencias}

Abass, A. (2014). Complete International Law: Text, Cases and Materials (2da. ed.). Oxford University Press.

Adhanom, T. (2020, 11 de marzo). Alocución de apertura del Director General de la OMS en la rueda de prensa sobre la COVID-19 celebrada el 11 de marzo de 2020. https://www.who.int/es/dg/speeches/detail/who-director-general-s-openingremarks-at-the-media-briefing-on-covid-19---11-march-2020

Alemania c. Polonia. (13 de septiembre de 1928). Corte Permanente de Justicia Internacional. $\quad$ https://www.icj-cij.org/files/permanent-court-of-internationaljustice/serie_A/A_17/54_Usine_de_Chorzow_Fond_Arret.pdf

BBC News Brasil. (2020, 29 de julio). Origen del coronavirus: el científico que asegura que China "encubrió" los primeros casos de covid-19 (y cómo eso empeoró la pandemia). https://www.bbc.com/mundo/noticias-internacional-53576076

BBC News Mundo. (2020, 26 de marzo). Coronavirus en China: el plan de Wuhan para levantar la cuarentena por la pandemia de covid-19. https://www.bbc.com/mundo/noticias-internacional-52040027

Benchikh, M. (2018). Droit International Public. Apopsix Editions.

Camerún c. Nigeria. (11 de junio de 1998). Corte Internacional de Justicia. https://www.icj-cij.org/files/case-related/94/094-19980611-JUD-01-00-EN.pdf

Casanovas, O. \& Rodrigo, A. (2018). Compendio de Derecho Internacional Público (7 $7^{\underline{a}}$ ed.). Editorial Tecnos.

Caso concerniente a las actividades militares y paramilitares en y contra Nicaragua. (27 de junio de 1986). Corte Internacional de Justicia. https://www.icjcij.org/files/case-related/70/070-19860627-JUD-01-00-EN.pdf

Caso concerniente al Proyecto Gabčíkovo-Nagymaros. (25 de septiembre de 1997). Corte Internacional de Justicia. https://www.icj-cij.org/files/case-related/92/09219970925-JUD-01-00-BI.pdf

CNN. (2020, 30 de marzo). 90 días de coronavirus: más de 770.000 casos y más de 36.000 muertes, y un tercio de la población mundial en cuarentena por una crisis que aún no ve su fin. https://cnnespanol.cnn.com/2020/03/30/cronologiacoronavirus-90-dias-700000-casos-34-000-muertes-cnn/

CNN Español. (2020, 20 de febrero). Cronología del coronavirus: así comenzó y se extendió el virus que tiene en alerta al mundo. https://cnnespanol.cnn.com/2020/02/20/cronologia-del-coronavirus-asicomenzo-y-se-extendio-el-virus-que-pone-en-alerta-al-mundo/

Convención relativa a las leyes y costumbres de la guerra terrestre, 18 de octubre de $1907 . \quad$ https://www.icrc.org/es/doc/resources/documents/misc/treaty-1907hague-convention-4-5tdm34.htm

Crawford, J. (2002). The International Law Commission's Articles on State Responsibility: Introduction, Text and Commentaries. Cambridge University Press.

Crawford, J. (2012). Brownlie's Principles of Public International Law (8 ${ }^{\underline{a}}$ ed.). Oxford University Press.

Crawford, J. \& Olleson, S. (2010). The nature and forms of international responsibility. En Malcom D., E. (Ed.), International Law (pp. 445 - 472). Oxford University Press.

Daillier, P., Forteau, M. \& Pellet, A. (2009). Droit International Public (8 $8^{\underline{a}}$ ed.). L.G.D.J. 
Departamento de Seguridad Nacional de España. (2020, 30 de enero). Coronavirus (2019-NCOV) 30 de enero 2020. https://www.dsn.gob.es/es/actualidad/salaprensa/coronavirus-2019-ncov-30-enero-2020

Dupuy, P. M. \& Kerbat, Y. (2014). Droit international public (12 $2^{-}$ed.). Dalloz.

El español. (2020, 07 de febrero). China censura la solidaridad con el médico que alertó del coronavirus y murió infectado. El español. Disponible en: https://www.elespanol.com/ciencia/salud/20200207/muere-coronavirus-liwenliang-medico-enfermedad-detenido/465703633_0.html

Etiopía c. Sudáfrica y Liberia c. Sudáfrica. (21 de diciembre de 1962). Corte Internacional de Justicia. https://www.icj-cij.org/files/case-related/46/046-19621221-JUD-0100-EN.pdf

Georgia c. Federación Rusa. (01 de abril de 2011). Corte Internacional de Justicia. https://www.icj-cij.org/files/case-related/140/140-20110401-JUD-01-00-EN.pdf

Grecia c. Reino Unido. (30 de agosto de 1924). Corte Permanente de Justicia Internacional. $\quad$ https://www.icj-cij.org/files/permanent-court-of-internationaljustice/serie_A/A_02/06_Mavrommatis_en_Palestine_Arret.pdf

Grecia c. Turquía. (19 de diciembre de $197 \overline{8})$. Corte Internacional de Justicia. https://www.icj-cij.org/files/case-related/62/062-19781219-JUD-01-00-BI.pdf

Grocio, H. (2005). The rights of war and peace (De jure belli ac pacis) (vol. 2). Liberty Fund Inc.

Introvigne, M. (2020, 14 de octubre). Coronavirus: CCP beware the Lawyers are coming. www.bitterwinter.org/coronavirus-ccp-beware-the-lawyers-are-coming/

Jiménez de Aréchaga, E. (1980). El derecho internacional contemporáneo. Editorial Técnos.

Ma, J. (2020, 13 de marzo). Coronavirus: China's first confirmed Covid-19 case traced back to November 17. South China Morning Post. https://www.scmp.com/news/china/society/article/3074991/coronavirus-chinasfirst-confirmed-covid-19-case-traced-back

Mercer, P (2020, 30 de abril). Australia-China Tensions Over Call for Global COVID-19 Probe. https://www.voanews.com/covid-19-pandemic/australia-china-tensionsover-call-global-covid-19-probe

Organización de las Naciones Unidas [ONU]. (2002). Tratados y Principios de las Naciones Unidas sobre el Espacio Ultraterrestre. Texto de los tratados y principios que deben regir las actividades de los Estados en la exploración y utilización del espacio ultraterrestre, aprobados por la Asamblea General de las Naciones Unidas, Nueva York. https://www.unoosa.org/pdf/publications/STSPACE11S.pdf

Organización de las Naciones Unidas [ONU]. (2006). Case concerning the difference between New Zealand and France concerning the interpretation or application of two agreements, concluded on 9 July 1986 between the two States and which related to the problems arising from the Rainbow Warrior Affair. https://legal.un.org/riaa/cases/vol_XX/215-284.pdf

Organización de las Naciones Unidas [ONU]. (2008). Draft articles on Responsibility of States for Internationally Wrongful Acts, with commentaries 2001. https://legal.un.org/ilc/texts/instruments/english/commentaries/9_6_2001.pdf

Organización de las Naciones Unidas [ONU]. (2020, 15 de abril). Cronología de la pandemia del coronavirus y la actuación de la Organización Mundial de la Salud. https://news.un.org/es/story/2020/04/1472862

Organización Mundial de la Salud [OMS]. (2006). Constitución de la Organización Mundial de la Salud. https://www.who.int/governance/eb/who_constitution_sp.pdf

Organización Mundial de la Salud [OMS]. (2008). 60 years World Health Organization. https://www.who.int/who60/media/exhibition_brochure.pdf 
Organización Mundial de la Salud [OMS]. (2016). Reglamento Sanitario Internacional (2005) (3a ed.). Ediciones de la OMS. https://apps.who.int/iris/bitstream/handle/10665/246186/9789243580494spa.pdf ;jsessionid=6EE716DA5A19BC4D35AA72E6A1103F76? sequence $=1$

Organización Mundial de la Salud [OMS]. (2020, 29 de junio): Cronología de la respuesta de la OMS a la COVID-19. https://www.who.int/es/news-room/detail/29-06-2020covidtimeline

Organización Mundial de La Salud [OMS]. (s.f.): Preguntas frecuentes sobre el Reglamento Sanitario Internacional (2005). https://www.who.int/ihr/publications/FAQ2009es.pdf?ua=1

Organización Panamericana de la Salud [OPS]. (2020, 28 de febrero). Actualización Epidemiológica Nuevo coronavirus (COVID-19). https://www.paho.org/sites/default/files/2020-02/2020-feb-28-phe-actualizacionepi-covid19.pdf

Pellet, A. (2010). The definition of responsibility in International Law. En Crawford, J., Olleson, S. \& Pellet, A. (Eds). The Law of International Responsibility (pp. 3 - 16). Oxford University Press, Oxford.

Portugal c. India. (26 de noviembre de 1957). Corte Internacional de Justicia. https://www.icj-cij.org/files/case-related/32/032-19571126-JUD-01-00-EN.pdf

Press, C. \& Jung, B. (2020, 08 de junio). Coronavirus: lo que los científicos han descubierto sobre el covid-19 en los 6 primeros meses de la pandemia. https://www.bbc.com/mundo/noticias-52959986

Raulaha, E. (2020, 08 de febrero). Chinese officials note serious problems in coronavirus response. The World Health Organization keeps praising them. The Washington Post. https://www.washingtonpost.com/world/asia_pacific/chinese-officials-noteserious-problems-in-coronavirus-response-the-world-health-organization-keepspraising-them/2020/02/08/b663dd7c-4834-11ea-91ab-ce439aa5c7c1_story.html

Reino Unido, Francia, Italia y Japón c. Alemania. (17 de agosto de 1923). Corte Permanente de Justicia Internacional. https://www.icj-cij.org/files/permanentcourt-of-international-justice/serie_A/A_01/03_Wimbledon_Arret_08_1923.pdf

Reino Unido de Gran Bretaña y el Norte de Irlanda c. Albania. (09 de abril de 1949). Corte Internacional de Justicia. https://www.icj-cij.org/files/case-related/1/00119490409-JUD-01-00-BI.pdf

Remiro, A., Riquelme, C., Orihuela, E., Díez-Hochleitner, J. \& Pérez-Prat, L. (2010). Derecho Internacional, Curso General. Editorial Tirant Lo Blanch.

Resolución 56/83. (12 de diciembre de 2001). Organización de las Naciones Unidas (Asamblea General). https://undocs.org/es/A/RES/56/83

Reuter, P. (1991). Trois observations sur la codification de la responsabilité international des États pour fait illicite. En Virally, M. (Ed.). Le droit international au service de la paix, de la justice et du développement (pp. 389-398). Pedone. http://www.sfdi.org/wp-content/uploads/2014/03/MelVirally.pdf

Ruzié, D. \& Teboul, G. (2015). Droit International Public (23를 ed.), Dalloz.

Shaw, M. (2011). International Law (6 $6^{\underline{a}}$ ed.). Cambridge University Press.

The Associated Press. (2020, 03 de junio). China delayed releasing coronavirus info, frustrating

WHO. https://apnews.com/article/3c061794970661042b18d5aeaaed9fae

Verdross, A. (1963). Derecho Internacional Público. Colección Jurídica Aguilar. 